\title{
Analysis of Loss of Flow Events on Brazilian Multipurpose Reactor Using the Relap5 Code
}

\author{
Humberto V. Soares, ${ }^{1,2}$ Ivan D. Aronne, ${ }^{3}$ Antonella L. Costa, ${ }^{1,2}$ \\ Claubia Pereira, ${ }^{1,2}$ and Maria Auxiliadora F. Veloso ${ }^{1,2}$ \\ ${ }^{1}$ Departamento de Engenharia Nuclear, Universidade Federal de Minas Gerais, Campus UFMG, \\ Avenida Antônio Carlos 6627, PCA1, Anexo Engenharia, Pampulha, 31270-901 Belo Horizonte, MG, Brazil \\ ${ }^{2}$ Instituto Nacional de Ciências e Tecnologia de Reatores Nucleares Inovadores/CNPq, UFRJ, \\ Avenida Pedro Calmon 550, Cidade Universitária, 21941-901 Rio de Janeiro, RJ, Brazil \\ ${ }^{3}$ Centro de Desenvolvimento da Tecnologia Nuclear, Comissão Nacional de Energia Nuclear, Campus UFMG, \\ Avenida Antônio Carlos 6627, Pampulha, 31270-901 Belo Horizonte, MG, Brazil
}

Correspondence should be addressed to Antonella L. Costa; antonella@nuclear.ufmg.br

Received 3 October 2013; Revised 21 February 2014; Accepted 24 February 2014; Published 3 June 2014

Academic Editor: Adem Acir

Copyright (C) 2014 Humberto V. Soares et al. This is an open access article distributed under the Creative Commons Attribution License, which permits unrestricted use, distribution, and reproduction in any medium, provided the original work is properly cited.

This work presents the thermal hydraulic simulation of the Brazilian multipurpose reactor (RMB) using a RELAP5/MOD3.3 model. Beyond steady state calculations, three transient cases of loss of flow accident (LOFA) in the primary cooling system have been simulated. The RELAP5 simulations demonstrate that after all initiating events, the reactor reaches a safe new steady state keeping the integrity and safety of the core. Moreover, a sensitivity study was performed to verify the nodalization behavior due to the variation of the thermal hydraulic channels in the reactor core. Transient calculations demonstrate that both nodalizations follow approximately the same behavior.

\section{Introduction}

The Brazilian Nuclear Energy Commission (Comissão Nacional de Energia Nuclear-CNEN) is leading the project of the Brazilian Multipurpose Reactor (RMB) envisaged to be projected, constructed, and operated to attend the present Brazilian need for a multipurpose neutron source, which will be able to supply the demand of radioisotopes, carry out material tests, and develop scientific, commercial, and medical applications with the use of neutron beams. The RMB will have three main functions: radioisotope production (mainly molybdenum), fuel, and material irradiation testing to support the Brazilian nuclear energy program. Moreover, it will provide neutron beams for scientific and applied research.

Among the different types of research nuclear reactors, the open pool reactors are the most common and the most used, because of their great versatility, easy operation, and safety. The reactors Osiris in France, and mainly the Australian research reactor OPAL (Open Pool Australian
Lightwater Reactor) projected by Argentina and built in Australia are being used as initial references for the RMB project.

In the present work, a nodalization for the RMB core using the RELAP5/MOD3.3 and the most important components of the pool loop and core loop circuits are presented. Loss of flow accidents have been performed for two types of nodalization changing the number of core thermal hydraulic channels to verify the sensitivity study.

1.1. The Use of RELAP5 for Research Reactors Simulation. The thermal hydraulic system code RELAP5 has been developed to best estimate transient simulation of light water power reactor systems during postulated accidents. Recent works have demonstrated that the code can be also used with good predictions for thermal hydraulic analysis of research reactors as it can be verified in the present literature [1-8].

Most of the research reactors operate at low-pressure levels and are subject to so-called thermal-hydraulic instabilities (THI) or flow excursion (FE) (known as Ledinegg-type 
instability) [9]. The occurrence of the onset of flow instability is due to an increase in the channel pressure drop resulting from high void generation in subcooled boiling regime. In systems subject to FE, initiation of boiling in one channel can lead to flow redistribution in the other adjacent channels, and under some critical conditions, this process can induce a flow starvation in the hot channel causing a local dryout or CHF. Consequently, the onset of flow instability (OFI) is considered as a limiting operating parameter for most types of research reactors [9-11]. Therefore, accurate determination of conditions that could induce the $\mathrm{FE}$ is of great importance for research reactor safety. According to the established postulate, the OFI corresponds to the minimum of the pressure drop characteristics versus mass flux curve [12]. Also, some authors have established criteria or empirical correlation for the determination of the thermal-hydraulic $(\mathrm{T} / \mathrm{H})$ conditions that may induce flow excursion [13-15]. It is also known that the onset of flow instability occurs at a flow rate slightly lower (or a heat flux slightly higher) than the flow rate (or heat flux) at which the onset of significant void occurs. Some authors consider the onset of significant void point as a conservative estimate of the onset of flow instability [16].

Therefore, some of these criteria are widely used and some of them are implemented in computer codes such as RELAP5/Mod3. In previous works, the assessment and validation of thermal-hydraulic system code have been performed in order to investigate the applicability of RELAP5/Mod3.2 to evaluate safety margins of an MTR research reactor [17]. The application of RELAP5/mod3 to research reactor has been already assessed $[5,18-20]$. Furthermore, the latest's version of RELAP5/Mod3.3 was made suitable for research reactor applications [21]. The code RELAP5/Mod3 assessment studies have shown good agreements with some limitations on the subcooled model $[5,19]$.

1.2. Characterization of the Design Basis Accidents (DBA) and Their Occurrence Probabilities. Postulated initiating events (PIEs) are events that have the potential to challenge the safety limits of the plant. They are the initiators of fault sequences. The primary causes of a PIE may be equipment failure and operator errors (both within and external to the reactor facility) and human-induced or natural events.

Following the guidance of the IAEA, a set of PIEs is assembled for assessment against the design of the replacement research reactor. This list covers all aspects of the design, operation, and utilization of research reactors [22]. Each PIE was then assessed to determine whether or not it is relevant to the design of the reactor facility. If it was considered relevant, then it was considered a design basis initiating event (DBIE) [23].

The PIE presented in the OPAL PSAR was obtained by systematic comparison of the IAEA list of initiating events [24] with the design of the facility. The accidents list, which were prepared for the OPAL reactor facility to describe the credible accidents are as follows:

(1) loss of electric power supplies;

(2) insertion of excess reactivity;

(3) loss of flow;
(4) loss of heat sink;

(5) loss of coolant in the primary cooling system (PCS);

(6) loss of coolant in the reactor and service pools cooling system (RSPCS);

(7) loss of heavy water;

(8) erroneous handling or failure of equipment or components;

(9) special internal events;

(10) reactor utilization malfunctions;

(11) spurious trigger of safety system components;

(12) external events;

(13) human factor.

According to OPAL safety analysis report (SAR) [25] the 16.19 item (beyond design basis accident, BDBA), on the basis of the analyses performed, a number of beyond design basis accident sequences have been identified that have the potential to lead to damage to the core or the irradiation rigs. The purpose of this section is to investigate these sequences further with a view to defining an accident to be used for emergency planning purposes.

Seven BDBA are identified for investigation:

(1) primary cooling system (PCS) pump shaft seizure with failure of the first shutdown system (FSS),

(2) reactor service pool cooling system (RSPCS) pump shaft seizure with failure to detect the loss of flow,

(3) partial blockage of cooling channels in a fuel assembly,

(4) erroneous early removal of a U-Mo rig into the hot cell,

(5) control bank withdrawal at nominal velocity during start up,

(6) control plate withdrawal during start up to low power operation with failure of the FSS and success of the secondary shutdown system (SSS), and

(7) total plant blackout for 10 days.

The OPAL PSAR [23] did not consider the failure of FSS in the first item cited before and, consequently, the failure of FSS was not considered in the simulation of this work.

Table 1 shows the initiating events frequency for the OPAL. The data are from the probabilistic safety assessment (PSA) document [26] referent to OPAL. In group B, we can see the initiating event frequency (per year) relative to loss of flow accident, and as it can be observed there is probability of occurrence of this event in consequence of the primary pump failure (B3).

Having identified initiating events and conducted the screening process, the initiating events were grouped and then quantified, either by using appropriate data from the sources already described [28-30] or, for more complex events, by developing fault trees. 
TABLE 1: Initiating Events Frequency for OPAL Reactor (adapted from [26]).

\begin{tabular}{llcc}
\hline Group/ID & Description & \multicolumn{2}{c}{ Initiating event frequency (per year) } \\
Mean & 5th percentile & $1.6 \times 10^{-3}$ \\
A & Reactivity transients & $7.3 \times 10^{-4}$ & $3.1 \times 10^{-3}$ \\
B & Loss of flow & & $7.4 \times 10^{-5}$ \\
B/B1 & Core bypass & $2.9 \times 10^{-7}$ & 3.0 \\
B/B2 & Loss of main power supply & 2.0 & $7.0 \times 10^{-2}$ \\
B/B3 & Primary pump failure & $4.6 \times 10^{-2}$ & $2.8 \times 10^{-4}$ \\
B/B4 & Primary isolation valve undesired closure & $3.4 \times 10^{-5}$ & $1.3 \times 10^{-5}$ \\
B/B5 & Fuel channel local blockage & & $3.9 \times 10^{-4}$ \\
C & Loss of coolant & $1.2 \times 10^{-6}$ & $4.9 \times 10^{-2}$ \\
D & Loss of heat sink & $1.2 \times 10^{-2}$ & $3.4 \times 10^{-4}$ \\
E & Mechanical damage to fuel assemblies & $3.0 \times 10^{-4}$ & $3.0 \times 10^{-2}$ \\
F & Heavy water leak & & $1.1 \times 10^{-3}$ \\
G & Events related to reactor utilization & $7.4 \times 10^{-5}$ & $1.4 \times 10^{-1}$ \\
\hline
\end{tabular}

According to OPAL safety analysis report (SAR), the probability of occurrence of a pump shaft seizure is considered to be very low due to the high quality of manufacture. No pathway has been identified for the intrusion of a foreign object in the PCS piping that could lead to pump shaft seizure. A protective grid is placed on top of the chimney during operation. An object fallen into the pool during refueling and sucked into the PCS piping would remain in the decay tank located between the reactor pool and the PCS pumps. The manufacturers of the PCS pumps use very large safety margins in the design of pump shafts and rotating machinery. Anticipatory signals would appear before shaft seizure. Vibration and high temperature in the pump motor would trigger alarms in the main control room. In order to protect the integrity of the pump, excess of mechanical vibration would cause automatic pump shutdown [25]. Even though shaft seizure is considered highly, unlikely, the seizure of a shaft with full sudden stoppage of the pump is considered to be within the design basis and was simulated in only one pump, because shaft seizure is considered so unlikely to occur at both pumps in the same time.

This work focuses the investigation of the time evolution of the temperature in the core, cladding, and pool reactor after a LOFA transient and their consequences.

\section{Brazilian Multipurpose Reactor}

The RMB will be an open pool multipurpose research reactor using low enriched uranium fuel, with a neutron flux higher than $2 \times 10^{14} \mathrm{n} /\left(\mathrm{cm}^{2} \mathrm{~s}\right)$ and $30 \mathrm{MW}_{\text {th }}$ of power. The reactor core will be compact using MTR fuel assembly type with planar plates and will be cooled and moderated by light water. A heavy water tank, which acts as a neutron reflector surrounds three quarters of the chimney in the core area working as reflector and enabling the extraction of neutron beams and the placement of materials for irradiation. In the remaining quarter there is beryllium that also works as reflector. The heavy water temperature will be controlled by a dedicated cooling system.

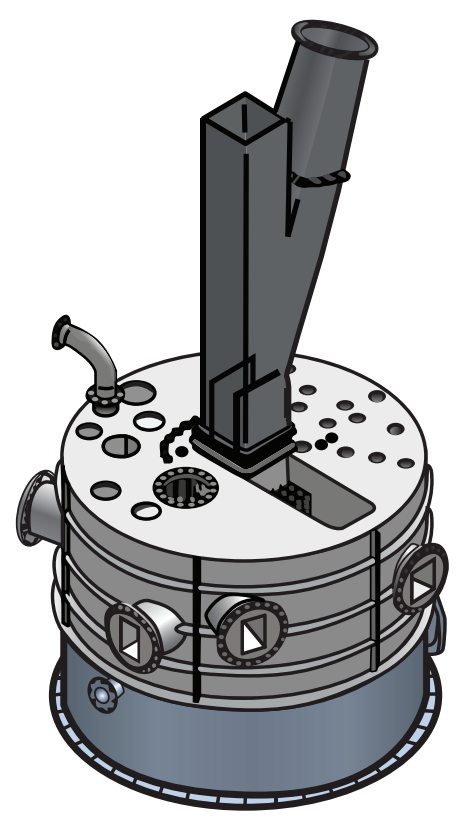

Figure 1: Heavy water tank of RMB [31].

There are no irradiation facilities within the reactor core. They are located only within the reflector vessel surrounding the core. The irradiation facilities are tubes inside the reflector vessel and specialized irradiation rigs can be placed within such tubes, as shown in Figure 1. Some of the irradiation facilities are light water cooled by forced downward-flow of light water from a dedicated cooling system serving the reactor pool and service pool. The reflector vessel includes a facility to accommodate a cold neutron source and provision for the possible addition of a hot neutron source. It also includes facilities to provide beams of neutrons for experiments to be located either within the reactor hall or the neutron guide hall.

The reactor cooling has four circuits: hot water layer (HWL), primary cooling system (PCS), reactor and service pools cooling system (RSPCS), and reflector cooling system 
TABLE 2: General characteristics of RMB (adapted from [27]).

\begin{tabular}{|c|c|}
\hline \multicolumn{2}{|c|}{ Reactor } \\
\hline Nominal power & $30 \mathrm{MW}_{\mathrm{th}}$ \\
\hline Coolant & Light water \\
\hline Reflector & $\mathrm{H}_{2} \mathrm{O}, \mathrm{D}_{2} \mathrm{O}$, Beryllium \\
\hline $\begin{array}{l}\text { Thermal and fast neutron flux in } \\
\text { the core }\end{array}$ & $>2.0 \times 10^{14}$ neutrons $\cdot \mathrm{cm}^{-2} \cdot \mathrm{s}^{-1}$ \\
\hline \multicolumn{2}{|l|}{ Core } \\
\hline Flow direction in core & Upwards \\
\hline Control rods drive location & Below core \\
\hline Grid array & $5 \times 5$ \\
\hline Dimensions & $0.51 \times 0.55 \times 0.815 \mathrm{~m}$ \\
\hline Number of fuel/control elements & $23 / 6$ \\
\hline Absorbing material & Ag-In-Cd \\
\hline Fuel assembly type & MTR (LEU) \\
\hline Nuclear fuel & $\mathrm{U}_{3} \mathrm{Si}_{2}$-Al enriched at $20 \%$ \\
\hline Fuel density & $4.8 \mathrm{gU} / \mathrm{cm}^{3}$ \\
\hline \multicolumn{2}{|c|}{ Cooling } \\
\hline $\begin{array}{l}\text { Core/pool inlet coolant } \\
\text { temperatures }(\mathrm{K})\end{array}$ & $311 / 306$ \\
\hline $\begin{array}{l}\text { Mass flow rate from pool to } \\
\text { chimney }(\mathrm{kg} / \mathrm{s})\end{array}$ & 83.3 \\
\hline $\begin{array}{l}\text { Inlet/outlet core mass flow rate } \\
(\mathrm{kg} / \mathrm{s})\end{array}$ & $750.0 / 833.3$ \\
\hline
\end{tabular}

(RCS). During normal operation at $30 \mathrm{MW}$ the PCS removes fission heat by forced upward circulation of demineralised water and transfers the heat to the secondary cooling system (SCS) via heat exchangers. The PCS also removes core decay heat by natural upward circulation of the water.

The whole core structure will be located within a square cross-section "core chimney" which constitutes part of the primary cooling circuit. The core will be cooled by a flow of demineralised light water moving upwards through the core. In normal operation, the coolant is pumped through the core and then through pipes to a heat exchanger before returning to the core inlet.

In order to reduce even more the radiation dose level inside the reactor building a heating and purification system maintains a nonactive stable HWL at the top of the pool. The HWL is utilized to stratify the pool water and avoid the incidence of radioactive water in the pool surface. Moreover, it provides radiation shielding necessary to protect reactor staff and also acts as a heat sink under certain abnormal conditions. The reactor shutdown will occur by two processes:

(i) the insertion of the six control plates into the core;

(ii) the partial drainage of the heavy water from the reflector vessel.

Both shutdown systems are physically independent as well as the instrumentation of each of them. The partial drainage of the heavy water from the reflector vessel may be considered as a back-up system that is only necessary if the first system fails.

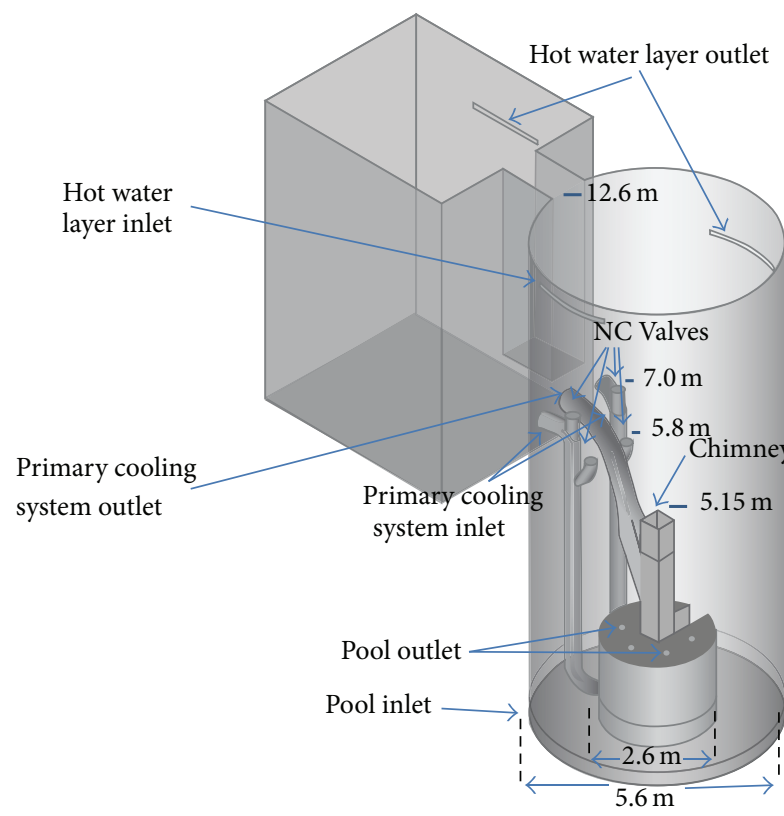

FIgURE 2: RMB present concept (adapted from [27]).

Table 2 presents the main characteristics of the RMB. Figure 2 shows the model of the present concept of the RMB reactor that was based on the Australian research reactor OPAL. The RMB pool is cylindrical having $12.6 \mathrm{~m}$ of height and $5.6 \mathrm{~m}$ of diameter.

The core is constituted of 23 plate-type fuel assemblies, two experimental assemblies, and two plate guide boxes. The box contains and protects six neutron-absorbing plates that can move upwards and downwards as shown in Figure 3.

The RMB will be a type of research reactors that is called MTR (materials testing reactor). The MTR fuel elements use fuel plates, which are quite common around the world. The basic MTR fuel element is an assembled set of aluminum fuel plates. It consists of regularly spaced plates forming a fuel assembly. These spaces allow a stream flow of water that serves as coolant and also as moderator to nuclear reaction. The fuel plates have a meat containing the fissile material, which is entirely covered with aluminum. Thus, currently the most advanced manufacturing technology commercially available for the MTR type fuel plates is based on the $\mathrm{U}_{3} \mathrm{Si}_{2}$ $\mathrm{Al}$ dispersion, with a concentration of $\mathrm{U}_{3} \mathrm{Si}_{2}$ resulting in a uranium density into the fuel meat of $4.8 \mathrm{gU} / \mathrm{cm}^{3}$, which is enriched with up to $20 \%$ of ${ }^{235} \mathrm{U}$ isotope (low enrichment), which is the nuclear fissile material. The fuel elements in the RMB will be constituted of 21 fuel plates according to Figure 4(a) with coolant channels between the fuel plates, as it can be seen in more detail in Figure 4(b).

\section{Thermal Hydraulic Model}

Figure 5 shows the RELAP5 MOD3.3 nodalization developed to simulate the RMB and Table 3 shows the correspondence between the main plant components and their equivalent components in the RELAP5 nodalization scheme. The reactor 


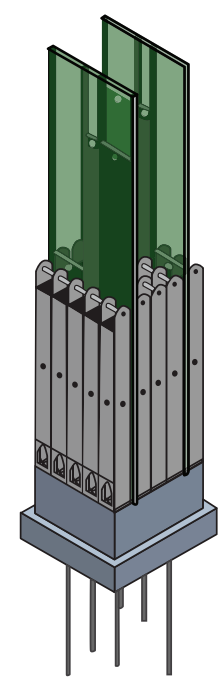

(a)

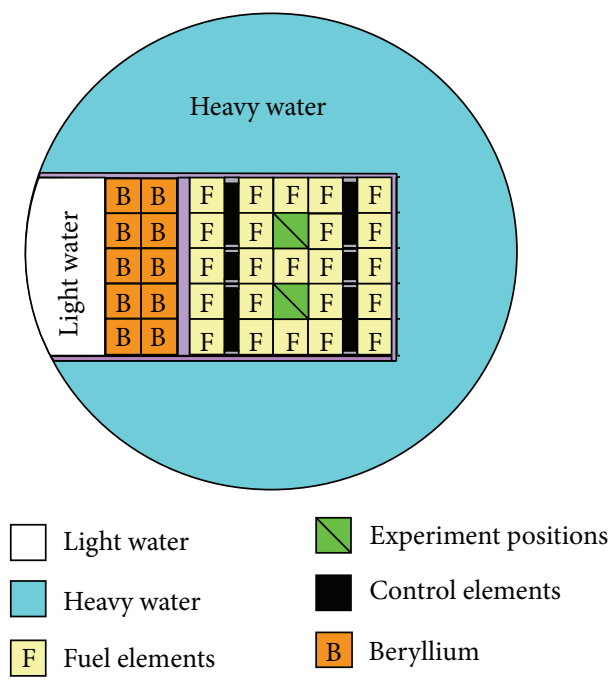

(b)

FIgURE 3: Representation of the RMB core (a) and its vicinity; upper view (b) [31].

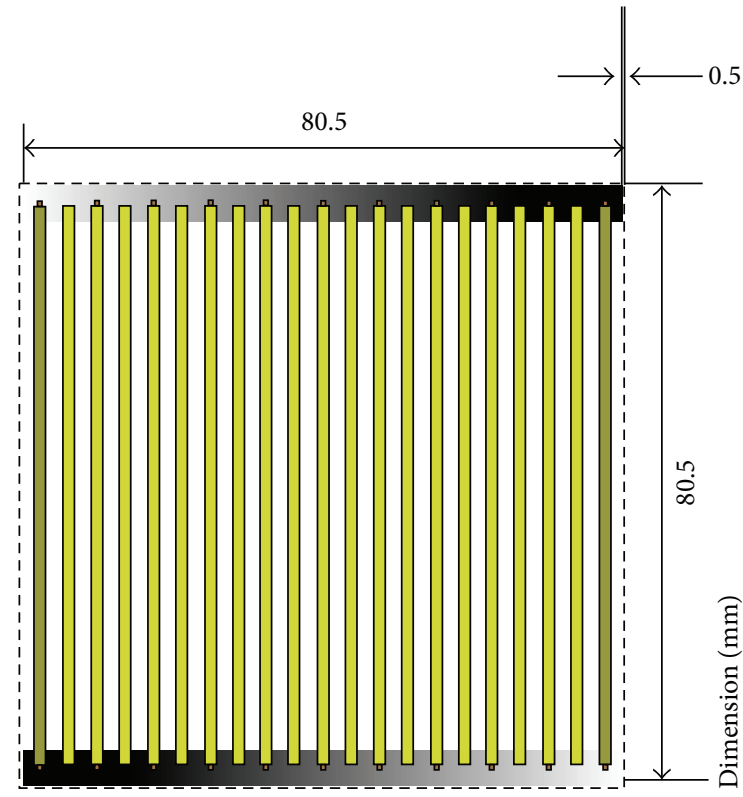

(a)

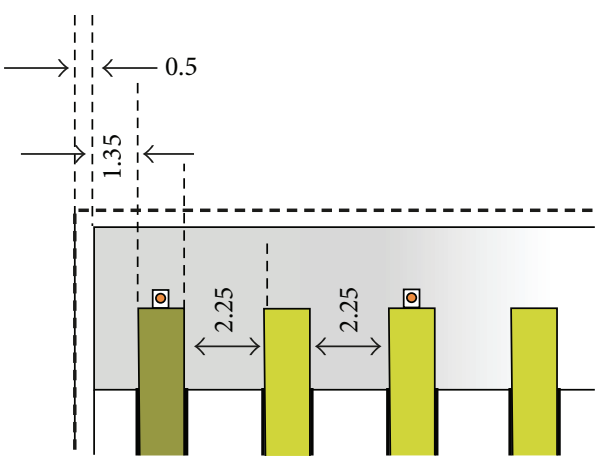

(b)

Figure 4: (a) RMB fuel element. (b) Fuel element in detail and quoin and distance between the plates (length in mm) [32].

pool was modelled using two pipe components (100 and 130) composed by twenty volumes each one. The heat generated by reactor in one side of the pool (100) leads to water circulation inside the pool through the cross junctions between the two pipes. The service pool was modelled using a pipe component (150) with twelve volumes. Volume 140 is a branch component that represents the upper pool surface, which is in contact with the atmosphere. Volume 190 is a time dependent volume that simulates the atmosphere on the top of pool surface.

The reactor and service pools cooling system (RSPCS) removes heat from the irradiation rigs in the reactor pool.
The system comprises two pipes inside the pool, the long term pool cooling pipe (component 202), and a pipe (component 204). Components outside the pool are the following: a decay tank (components 222-226), a main pump (component 230), heat exchanger (component 234; primary side), a three-way valve (simulated by valves 209 and 211), and associated components. The position of the three-way valve defines which of the two lines is connected to the pumping equipment to perform forced circulation. The rigs cooling branch has a pipe (component 204) that extends from the irradiation rig plenum below the reflector vessel and passes through the 
TABLE 3: Main nodalization components and their input identifier number.

\begin{tabular}{lc}
\hline Component & Identifier \\
\hline Reactor pool & 100 and 130 \\
Reactor pool cooling system (RPCS) & $201-239$ \\
Reactor core & 316 \\
Reactor chimney & 340 \\
Primary cooling system (PCS) & $400-460$ \\
Heavy water tank & 500 \\
Reflector cooling system (RCS) & $500-530$ \\
Natural convention valves (flap valves) & 364 and 367 \\
Siphon breakers valves & 243,363 and 353 \\
Pool atmosphere simulator & 190 \\
Decay tank of PCS & $402-406$ \\
Decay tank of RPCS & $222-226$ \\
Pumps of PCS & 410 and 412 \\
Pump of RPCS & 230 \\
Primary side heat exchanger of PCS & 430 \\
Secondary side heat exchanger of PCS & $800-820$ \\
Primary side heat exchanger of RPCS & 234 \\
Secondary side heat exchanger of RPCS & $700-720$ \\
Primary side heat exchanger of RCS & 530 \\
Secondary side heat exchanger of RCS & $900-920$ \\
\hline
\end{tabular}

reactor pool boundary at level $+7.00 \mathrm{~m}$ inside the pool. From there, it is connected to the three-way valve and then to the decay tank.

The primary cooling system (PCS) comprises components 300 through 360 which are inside the pool and components 400 through 460 which are outside the reactor pool. Component 300 represents the core inlet lower plenum which conducts the light water to the core (component 316). The core has one hydrodynamic channel with only one heat structure (HS) associated to it representing all fuel plates. The heated water goes through the components 320 and 330 where it is mixed with a small downward flow coming from the pool through the chimney (component 340). The chimney flow corresponds about $10 \%$ of the total outlet flow of the PCS.

In order to allow the establishment of natural circulation when the PCS pumps are not in operation three special flap valves are located in two lines returning to the pool, which are represented by component 360 . One set of valves is located at level $+7.00 \mathrm{~m}$ and is represented by valves 363 and 364 and the other set, at level $+5.80 \mathrm{~m}$, is modeled by the valve 367 . Both sets are above the upper edge of the chimney at level $+5.15 \mathrm{~m}$ (component 340 ). Each set of these special valves is modeled by two valves, one trip valve and one check valve. Valve 363 is a trip valve and the components 364 and 367 are check valves. Both valve types behave as on/off switch. During a loss of coolant accident (LOCA) the coolant is lost by a rupture and the water level of the reactor pool drops until to reach the upper flap valves, which will act as siphon breakers and will prevent the water level to decrease below
$+7.00 \mathrm{~m}$. The lower flap valves will open, thus creating the natural circulation cooling flow path. Only one of the two valves is required to provide a flow sufficient to remove core decay heat.

The main components of PCS outside the pool are the following: a tank for nitrogen-16 decay (components 402406), two parallel primary cooling pumps (components 410 and 412), the main heat exchanger (component 430; primary side), valves (components 407, 409, 423, and 425), and pipe components.

The reflector coolant system, RCS, is composed of a heavy water tank (component 500) and its heat exchanger circuit (component 530; primary side and component 910; secondary side).

The area located on level $-5.00 \mathrm{~m}$ (under the pool ground level) accommodates the pumps of the cooling systems, heat exchangers, and associated components of both circuits PCS and RSPCS.

The RELAP5 point kinetics model was used to estimate the fuel power in the simulations.

\section{Steady State Calculation}

Several thermal hydraulic parameters have not been established in the RMB project and frequently there are changes on their values and definitions. Experiments to verify the RMB behavior are still being planned and, therefore, there are not experimental data to compare with the results of RELAP5 calculation. However, the mass flow rate and temperature in the core has been defined based on the OPAL reactor and they have been used as input data for the RELAP5 model. Table 4 shows the steady-state calculations with RELAP5 performed at $30 \mathrm{MW}$ and the comparison with some reference values [27]. As it can be seen in Table 4, the analyzed steady state parameters showed very good agreement with the reference considering the RELAP5 users acceptable error.

\section{Transient Calculation}

A LOFA may arise through failures associated with the PCS pumps or events resulting in a decrease in the primary coolant flow with the PCS pumps working normally. Many types of loss of flow events were identified by PIEs, but only two types of loss of flow events were identified as the DBIEs.

The two DBIEs identified for analysis were as follows:

(i) single pump shaft seizure;

(ii) failure of two pump motors.

Three transient cases were performed using the RELAP5 code to simulate LOFAs as described in Table 5.

All transient events started at 20,000 seconds after the simulation of steady state at $30 \mathrm{MW}$. Figure 6 shows the mass flow rate and the head of pump 412 evolution in the PCS pumps during a motor failure (case 1) and a shaft seizure (case 2 ). In case 1 , the slow pump coast down provided a slow decrease in its mass flow for about 40 seconds. On the other hand, in case 2, the mass flow in pump 410 was interrupted immediately after the trip command causing a 


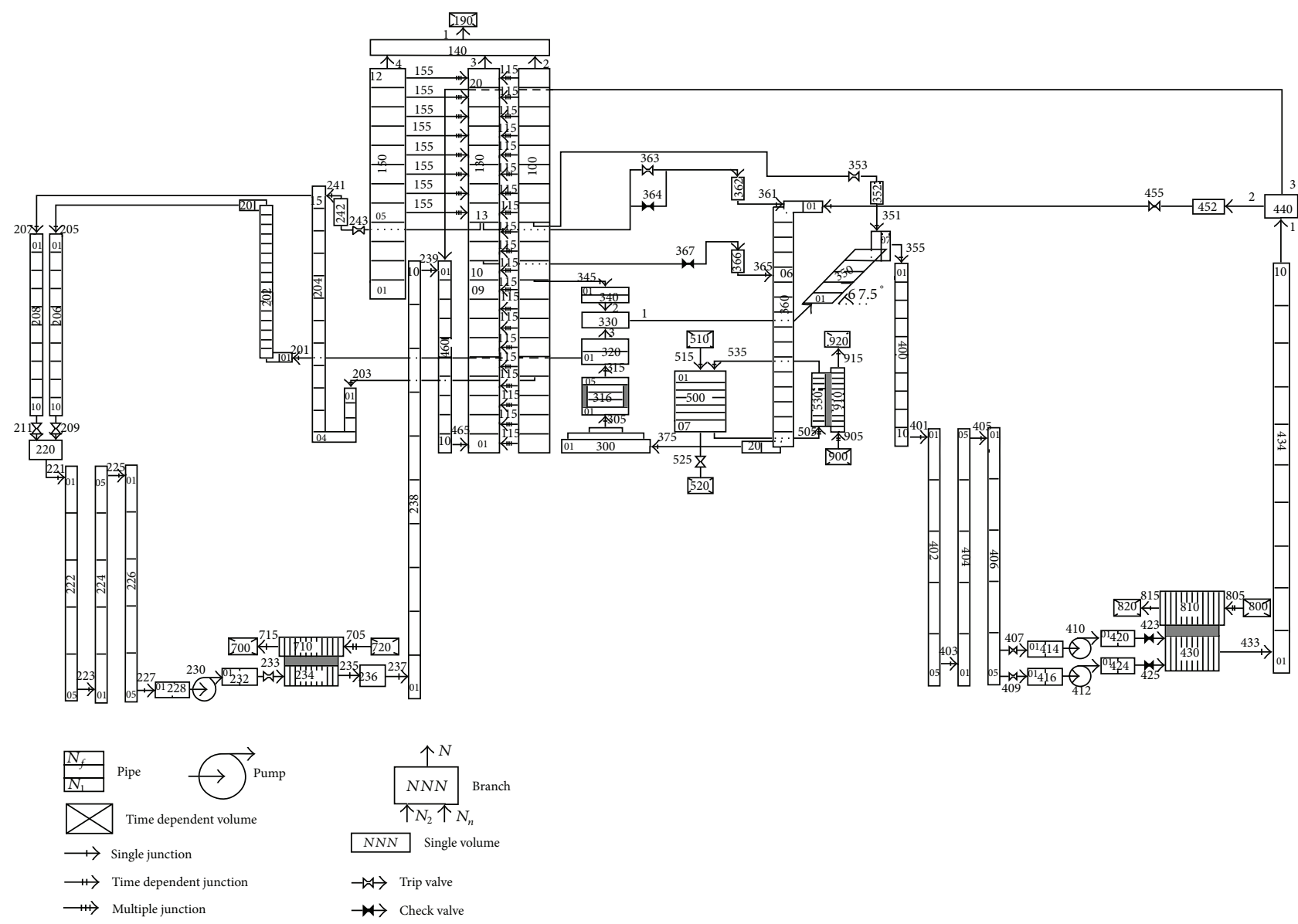

FIGURE 5: RMB nodalization for RELAP5.

TABLE 4: Reference and calculated results for $30 \mathrm{MW}$ power condition.

\begin{tabular}{lcccc}
\hline Parameters & Reference & RELAP5 & Error (\%) & Acceptable error (\%) \\
\hline Inlet and outlet core coolant temperatures (K) & $311.0 / 320.0$ & $311.0 / 320.0$ & $0.0 / 0.0$ & 0.5 \\
Inlet and outlet pool coolant temperatures (K) & $306.0 /-$ & $307.0 / 312.3$ & 0.4 & 0.5 \\
Mass flow rate from pool to core by chimney $(\mathrm{kg} / \mathrm{s})$ & 83.3 & 83.1 & 0.2 & 2.0 \\
Inlet and outlet core mass flow rate $(\mathrm{kg} / \mathrm{s})$ & $750.0 / 833.0$ & $748.0 / 831.0$ & $0.2 / 0.2$ & 2.0 \\
\hline
\end{tabular}

${ }^{*}$ Error $=100 \times($ calculation - reference $) /$ reference.

TABLE 5: Simulated cases in the PCS pumps.

\begin{tabular}{lccc}
\hline Case & Pump 410 & Pump 412 & Core cooling \\
\hline 1 & Motor failure & Running & Forced circulation \\
2 & Shaft seizure & Running & $\begin{array}{c}\text { Forced circulation } \\
\text { Fly-wheel controlled forced } \\
\text { circulation/natural } \\
\text { circulation }\end{array}$ \\
\hline
\end{tabular}

sudden reduction in flow, with the shaft seizure obstructing the flow coast down provided by the pump inertia. As it can be seen in Figure 6, the fail in the pump 410 caused the mass flow to increase in the parallel pump (412), in both cases. This fact can be explained by decrease of the pressure loss in the primary cooling loop due to the mass flow rate decrease in this circuit; consequently this caused the pump head drop in the pump 412 and the increase in its mass flow rate, which characterizes a change of the operation point in the pump curve.

Verifying Figure 6 is possible to see the sharp increase in the mass flow rate of the pump 412 (as it can be seen in detail in Figure 6 inside the black circle). Before the event, the water of the circuit is sucked by two parallel pumps. When a pump stops working suddenly by shaft seizure, obstructing then the water flow on the circuit, the water inertia impels the other pump (412) that receives much more fluid than before. Therefore, by a fast moment, the pump works as a turbine, that is, the fluid pushes the pump impeller. After this, the mass flow rate decreases due to the pressure loss and the pump returns its operation mode in another point of its curve with the consequent recovery of the pump head. 


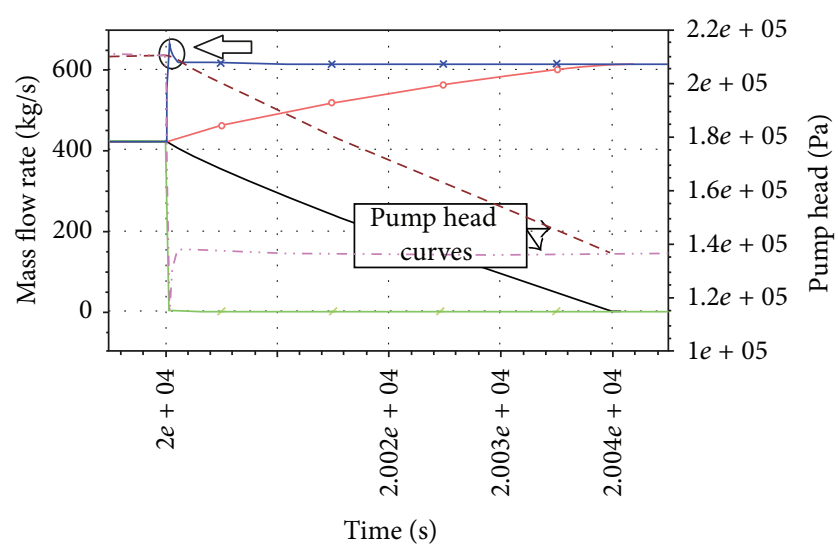

$\begin{array}{ll}\text { — Case 1-pump 410 } & \text { * Case 2-pump 412 } \\ \multimap \text { Case 1-pump 412 } & -- \text { Case 1-pump head } 412 \\ - \text { Case 2-pump 410 } & \text {-... Case 2-pump head } 412\end{array}$

FIgURE 6: Mass flow rate evolution of pumps 410 and 412 and pump 412 head in cases 1 and 2.

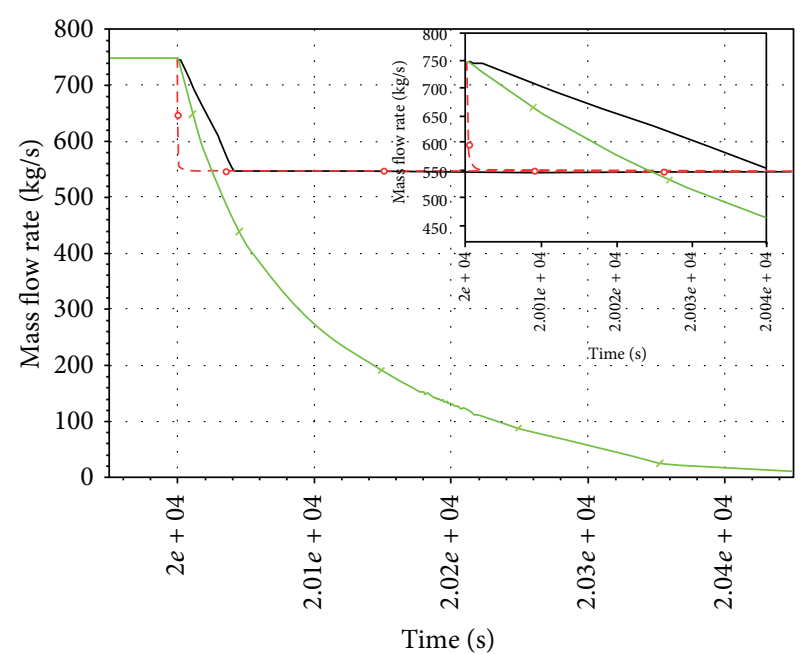

$$
\begin{aligned}
& \text { - Case 1-core inlet } \\
& \text { - - Case 2-core inlet } \\
& \text { — Case 3-core inlet }
\end{aligned}
$$

FIGURE 7: Mass flow rate evolution in core inlet in all cases analyzed.

Figure 7 shows the mass flow rate in core inlet for the three cases. The motor failure in both pumps (case 3) caused slow mass flow rate decrease in core inlet, for about 400 seconds (about ten times higher than case 1). The mass flow in core inlet to steady state is $750 \mathrm{~kg} / \mathrm{s}$ and after of motor failure and shaft seizure of the pump 410 (cases 1 and 2) the mass flow was reduced to about $550 \mathrm{~kg} / \mathrm{s}$ ( $73.3 \%$ of steady state value). Forced circulation through the core reduces according to the dynamics of the pump flywheel. During the first second of calculation, the flow is governed by the abrupt seizure of the shaft of one of the pumps (410) in case 2. Thereafter, the mass flow rate reflects the new force balance between the torque of the slowing of the pump 412 and the losing in the circuit friction.

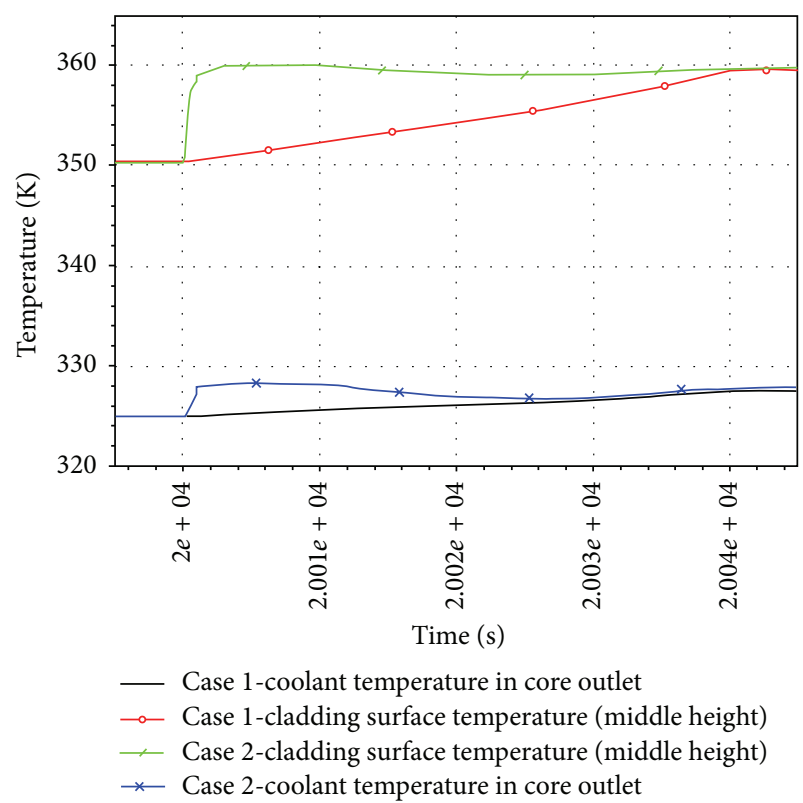

FIGURE 8: Coolant temperature evolution in core outlet and cladding surface temperature in cases 1 and 2 .

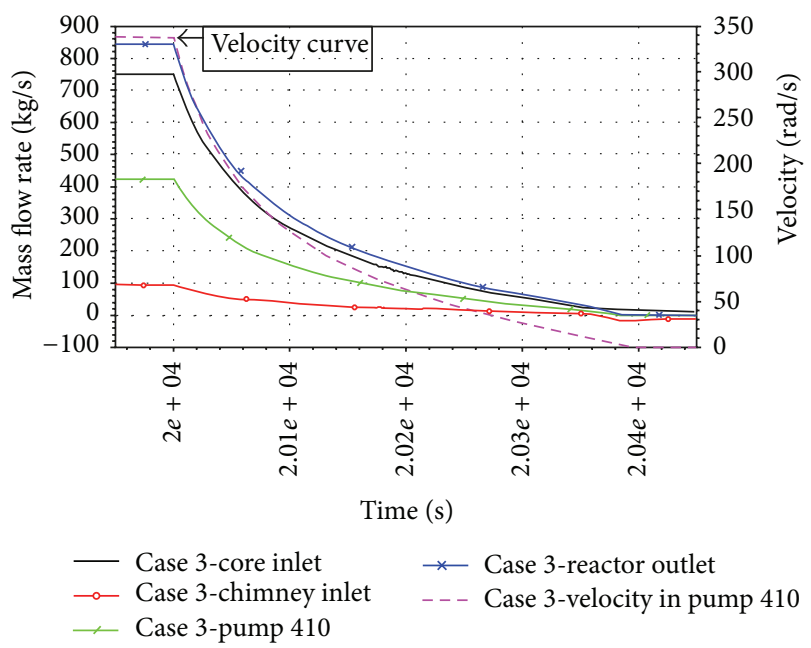

FIgURE 9: Mass flow rate (core and chimney inlet and reactor outlet) and pump velocity (410) evolution in case 3 .

Outlet core coolant temperature and cladding surface temperature (midheight) in case 1 increased slowly for about 40 seconds up to reach the new steady state (Figure 8), according to the slow mass flow rate reduction in core inlet (Figure 7). On the other hand, in case 2, the coolant temperature in core outlet and cladding surface temperature (midheight) increased abruptly (in few seconds) and reached practically the same new steady state of that in case 1 .

In the case of both PCS pumps have a motor disconnection or failure, or if the power to the pump motors is lost (case 3 ), a very slow reduction in the mass flow in PCS is caused as it can be seen in Figure 9. Figure 9 shows also the velocity curve of the pump 410 . Such curve reached null velocity at 


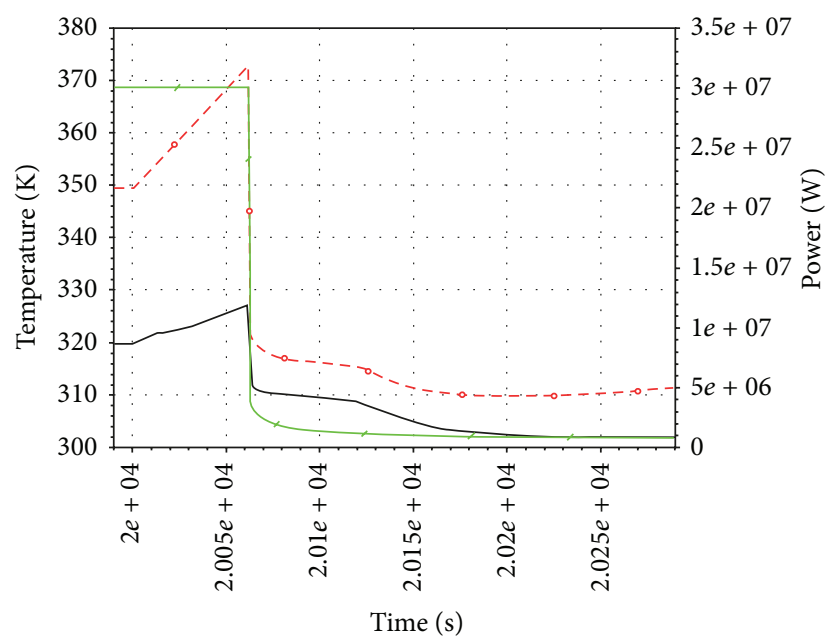

- Case 3-coolant temperature in core outlet

- - Case 3-cladding surface temperature (middle height)

$\rightarrow$ Case 3-reactor power

Figure 10: Coolant and cladding temperatures and reactor power evolution in case 3 .

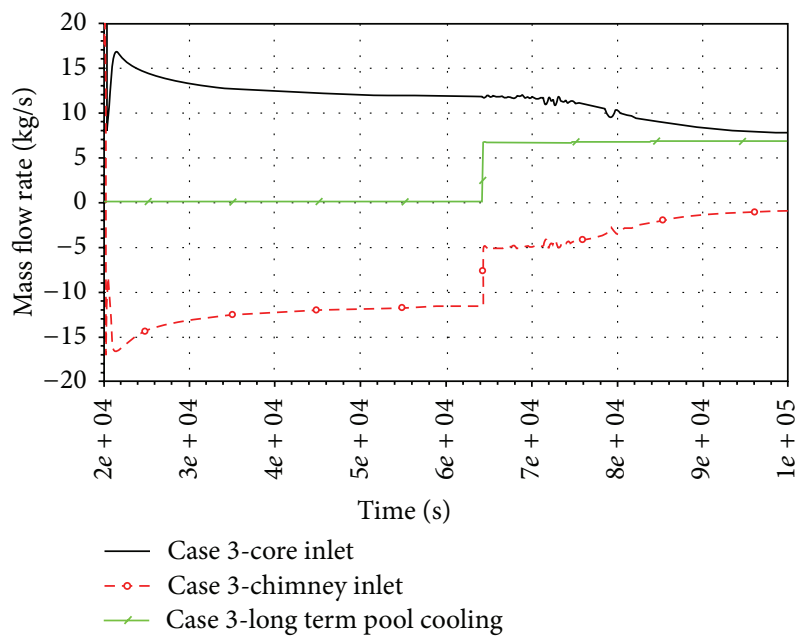

FIGURE 11: Mass flow rate evolution showing natural circulation mode to the case 3 .

about 400 seconds after the beginning of the transient in both pumps. The curve relative to the mass flow in the pump 412 and its velocity curve demonstrate the same behavior of the pump 410.

To simulate the first shutdown system (FSS) action (insertion of all control plates in core) using the RELAP5, $\$ 10$ of negative reactivity was inserted in 0.5 seconds of simulation time, when the mass flow in core inlet decreases below $50 \%$ of steady state value. In case 3 , this happened at about 60 seconds after the pumps trip, as it can be verified in Figure 10. The coolant temperature in the core outlet and cladding surface temperature (midheight) reached about $327 \mathrm{~K}$ and $372 \mathrm{~K}$, respectively, after 60 seconds of transient. However, after the reactor shutdown, both temperatures dropped abruptly to new steady state values.

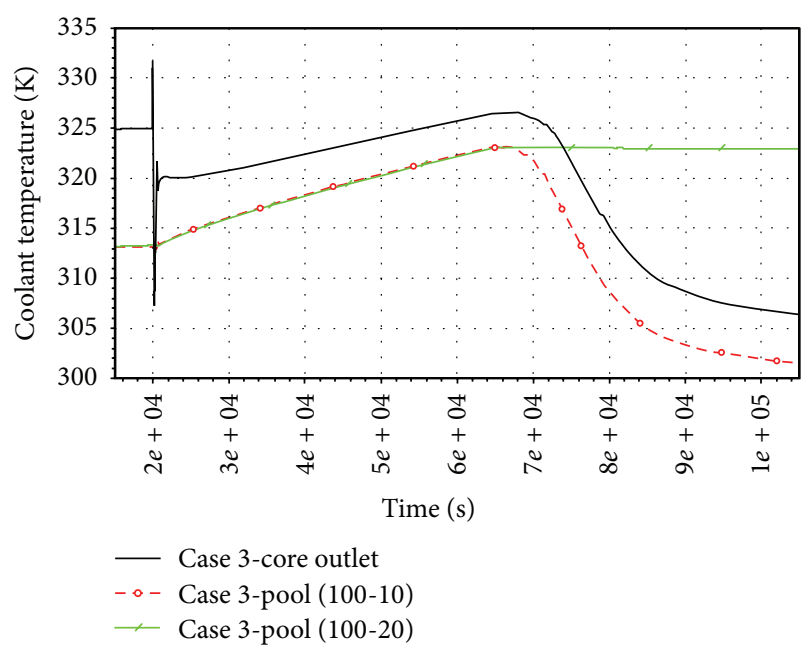

FIGURE 12: Coolant temperature in core outlet and two pool levels in case 3.

Figure 11 shows the mass flow rate in the core inlet and chimney inlet and the long term pool cooling system going into operation in case 3 for an interval of 100,000 s of calculation. At about $380 \mathrm{~s}$ after the pumps trip, the mass flow rate in chimney inlet changes its direction, of downwards to upwards, as verified in Figure 11. This fact occurred due to the mass flow interruption in reactor outlet and, therefore, the hot water generated in core rises and flows out by chimney causing the natural circulation. Automatically, the flap valves (364 and 367) open providing the cooling in reactor core. Both natural circulation valves provide about $12 \mathrm{~kg} / \mathrm{s}$ of mass flow that is enough to ensure the heat removal from the core.

The long term pool cooling came into operation at about 44,000 seconds after the pumps trip as it can be seen in Figure 11. The long term pool cooling mode of the RSPCS provides an additional significant safety contribution by maintaining the reactor pool temperature within its nominal operating range. During the normal reactor shutdown state, the core cooling by natural circulation takes place while the RSPCS removes heat from the reactor pool in its long term pool cooling mode. Such pool cooling is not necessary to remove heat to ensure core integrity; it is only an additional safety parameter. This system acts (using a trip in the RELAP5 input desk) when the coolant temperature in the middle of the pool (100-10) reaches $323 \mathrm{~K}$ (Figure 12).

In the long term pool cooling mode, the pump takes water from the chimney just above the core (component 320). This position of the suction point for the RSPCS has the advantage that it reduces the flow that, having gone through the core as a result of natural circulation, would otherwise reach the upper level of the pool. Thus, the flow is prevented from disturbing the reactor pool hot water layer system. Moreover, due to its location above the core, the suction line of the long term pool cooling mode will receive a large portion of the core decay heat removed by natural circulation.

Figure 12 shows the coolant temperature in core outlet and two pool levels (100-10 and 100-20). Both coolant temperatures increase slowly. However, when the long term 


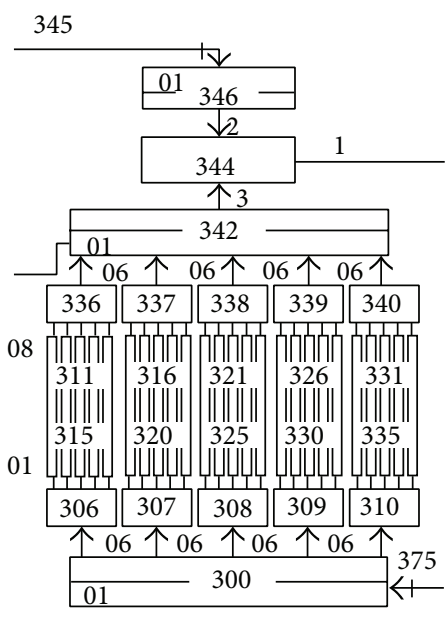

(a)

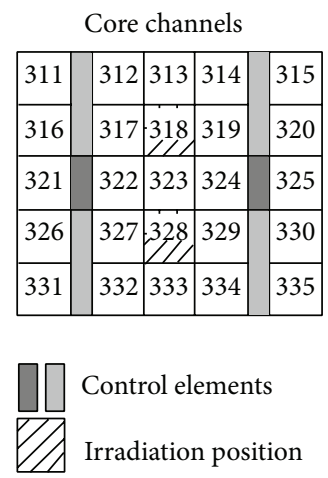

(b)

FIGURE 13: RMB core nodalization using 25 thermal hydraulic channels (a) and its upper view (b).

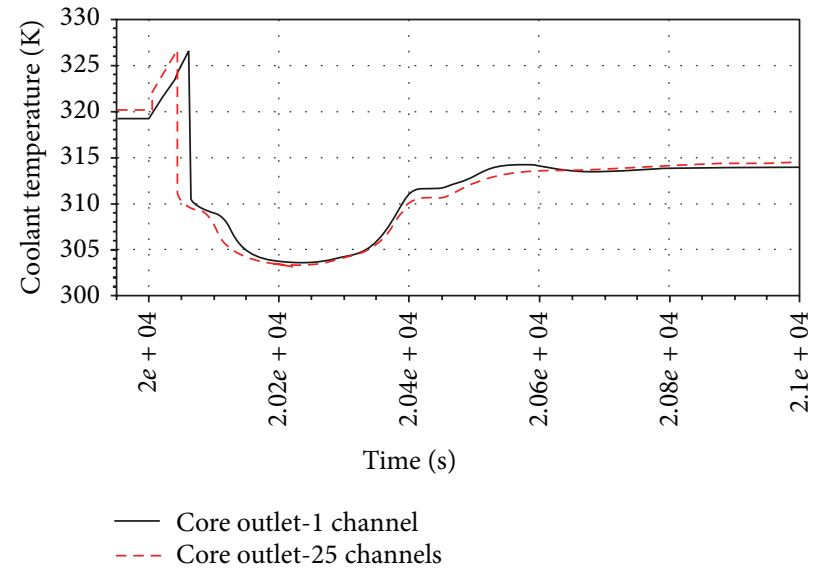

FIGURE 14: Coolant temperature in core outlet for 1 thermal hydraulic channel and 25 thermal hydraulic channels in the RMB core for motor failure in both PCS pumps.

pool cooling system is working, the coolant temperature in the core outlet and in the pool midheight begins to decrease slowly. On the other hand, the coolant temperature in pool top remains at the same value of before of the long term pool cooling system to operate due to Hot Water Layer system.

5.1. Sensitivity Test: Modification in the Thermal Hydraulic Channels Quantity. To perform a sensitivity study, the nodalization has been modified in relation to the original core model. Figure 13 shows the RMB core nodalization in the RELAP 5 code considering 25 thermal hydraulic channels and 23 heat structures. The thermal hydraulics channels were simulated using pipes components (311-335). These channels are connected in the component branches (core inlet 306310 , core outlet 336-340). Some components above the core changed the identification numbers in relation to the original nodalization shown in Figure 5.

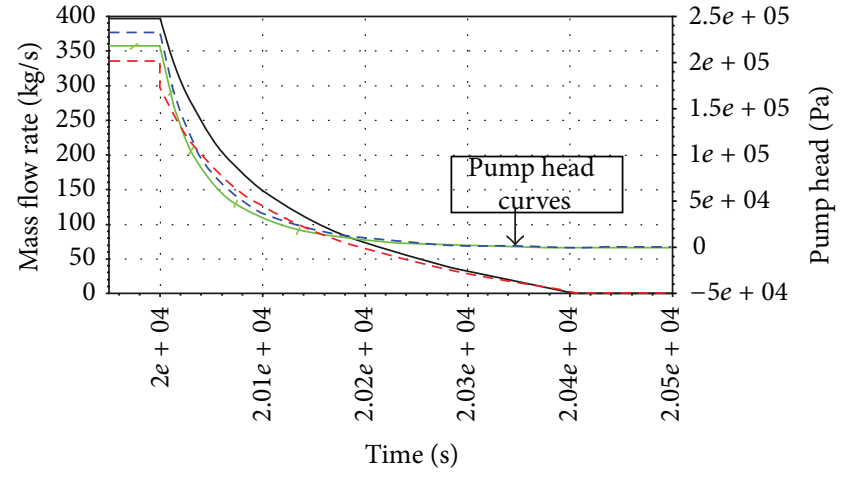

- Mass flow curve-1 channel

- - - Mass flow curve-25 channels

- Pump head curve-1 channel

- - - Pump head curve-25 channels

FIgURE 15: Mass flow rate and pump head evolutions during a motor failure in both PCS pumps for nodalizations with 1 thermal hydraulic channel and 25 thermal hydraulic channels in the core.

Figure 14 shows the coolant temperature in the core outlet for motor failure case in both PCS pumps (410 and 412) with the core nodalization of thel thermal hydraulic channel and with 25 thermal hydraulic channels. As can be seen, the curves have the same behavior; however, the coolant temperature is not the same values before the accident.

Figure 15 shows the mass flow rate and the pump head evolution during a motor failure in both PCS pumps for considering the nodalizations with 1 thermal hydraulic channel and 25 thermal hydraulic channels in the core. The curves present a behavior similar during the accident. In both cases, the mass flow rate reach the zero value in the same time after $400 \mathrm{~s}$ of the beginning of the transient. The values in the steady state are slightly different comparing the two nodalizations because the forward energy loss coefficients on the pipes were not adjusted on the circuit. However, both nodalizations presented the same behavior in the analyzed transient. 


\section{Conclusions}

The Brazilian Multipurpose Reactor (RMB) will have many functions with the main utilization for radioisotopes production to medical applications. Several characteristics of the OPAL reactor have been used in the initial project of the $\mathrm{RMB}$. The development of the RMB is on the initial phase of theoretical calculations.

The thermal hydraulic model in RMB was presented in this work using RELAP5 code. After several tests, the steady state operation condition was reached at $30 \mathrm{MW}$ with all thermal hydraulic parameters in stable behavior. Thereafter, a loss of flow accident (LOFA) was simulated.

Three cases of primary cooling system (PCS) pumps failure were simulated being the following: pump motor failure (case 1), pump shaft seizure (case 2), and pump motor failure in two pumps (case 3). The analysis of the loss of flow transients shows that the reactor remains in a safe operation state for the studied cases. Cases 1 and 2 did not cause the action of first shutdown system (FSS), because the mass flow in core inlet was above of level established, and the reactor reached a safe new steady state. The simultaneous failure of both PCS pump motors (case 3) leads to a safe shutdown state, with the reactor operating in natural circulation cooling mode. During the transient after the failure of both pump motors, the temperature of the fuel assembly cladding remains below the onset of nucleate boiling value and the coolant did not reach the saturation temperature.

A sensitivity study has been performed where the nodalization has been modified in relation to the original core model from 1 thermal hydraulic core channel to 25 channels. Both nodalizations presented the same behavior in the analyzed transient in spite of the values found in the steady state were slightly different comparing the two nodalizations because the forward energy loss coefficients on the pipes were not adjusted on the circuit. It will be verified in future work. Moreover, an uncertainty calculation related to the obtained data is need and will be presented also in a future paper.

\section{Conflict of Interests}

The authors declare that there is no conflict of interests regarding the publication of this paper.

\section{Acknowledgments}

The authors are grateful to CAPES, CDTN/CNEN, FAPEMIG, and CNPq for the support.

\section{References}

[1] A. R. Antariksawan, M. Q. Huda, T. Liu, J. Zmitkova, C. M. Allison, and J. K. Hohorst, "Validation of RELAP/SCAPSIM/MOD3. 4 for research reactor applications," in Proceedings of the 13th International Conference on Nuclear Engineering, pp. 1-8, Beijing, China, 2005.

[2] C. B. Davis, "Applicability of RELAP5/MOD3. 2 to research reactors," in Proceedings of the IAEA Regional Training Workshop on Safety Analysis Methodology and Computer Code Utilization, KINS, Daejeon, Republic of Korea, 2002.
[3] B. Di Maro, F. Pierro, A. Bousbia Salah, and F. D’Auria, “Analysis of a pump trip in a typical research reactor by RELAP5/MOD 3.3," in Proceedings of the International Congress on Advances in Nuclear Power Plants (ICAPP '03), Cordoba, Spain, 2003.

[4] A. L. Costa, P. A. L. Reis, C. Pereira, M. A. F. Veloso, A. Z. Mesquita, and H. V. Soares, "Thermal hydraulic analysis of the IPR-R1 TRIGA research reactor using a RELAP5 model," Nuclear Engineering and Design, vol. 240, no. 6, pp. 1487-1494, 2010.

[5] T. Hamidouche, A. Bousbia-Salah, M. Adorni, and F. D'Auria, "Dynamic calculations of the IAEA safety MTR research reactor Benchmark problem using RELAP5/3.2 code," Annals of Nuclear Energy, vol. 31, no. 12, pp. 1385-1402, 2004.

[6] A. Khedr, M. Adorni, and F. d'Auria, "The effect of code user and boundary conditions on RELAP calculations of MTR research reactor transient scenarios," Nuclear Technology and Radiation Protection, vol. 1, pp. 16-22, 2005.

[7] B. Končar and B. Mavko, "Modelling of low-pressure subcooled flow boiling using the RELAP5 code," Nuclear Engineering and Design, vol. 220, no. 3, pp. 255-273, 2003.

[8] P. A. L. Reis, A. L. Costa, C. Pereira et al., "Assessment of a RELAP5 model for the IPR-R1 TRIGA research reactor," Annals of Nuclear Energy, vol. 37, no. 10, pp. 1341-1350, 2010.

[9] IAEA, Research Reactor Core Conversion From the Use of High Enriched Uranium to the Use of Low Enriched Uranium Fuels Guidebook, IAEA-TECDOC-233, IAEA, Vienna, Austria, 1980.

[10] R. B. Rothrock, "Thermal hydraulic bases for the safety limits and limiting safety system for the HFIR operating at $100 \mathrm{MW}$ and 468 psig primary system, using specially selected fuel elements," Tech. Rep. ORNL/TM-13694, 1998.

[11] L. W. Hu and J. A. Bernard, "Thermal hydraulic criteria for the MIT research reactor safety limits calculations," Transactions of the ANS, vol. 91, pp. 114-115, 1999.

[12] J. S. Maulbetsch and P. Griffith, "A study of system-induced instabilities in forced convective flows with subcooled boiling," MIT TR 5382-35, 1965.

[13] R. H. Whittle and R. Forgan, "A correlation for the minima in the pressure drop versus flow-rate curves for sub-cooled water flowing in narrow heated channels," Nuclear Engineering and Design, vol. 6, no. 1, pp. 89-99, 1967.

[14] P. Saha and N. Zuber, "Point of net vapor generation and vapor void fraction in subcooled boiling," in Proceedings of the 5th International Heat Transfer Conference, vol. 4, Tokyo, Japan, September 1974.

[15] R. B. Duffey and E. D. Hughes, "Static flow instability onset in tubes, channels, annuli, and rod bundles," International Journal of Heat and Mass Transfer, vol. 34, no. 10, pp. 2483-2496, 1991.

[16] G. R. Warrier and V. K. Dhir, "Review of experimental and analytical studies on low pressure subcooled flow boiling," in Proceedings of the 5th ASME/JSME Joint Thermal Engineering Conference, San Diego, Calif, USA, March 1999.

[17] T. Hamidouche and A. Bousbia-Salah, "RELAP5/3.2 assessment against low pressure onset of flow instability in parallel heated channels," Annals of Nuclear Energy, vol. 33, no. 6, pp. 510-520, 2006.

[18] T. Hamidouche, A. Bousbia-Salah, E. K. Si-Ahmed, M. Y. Mokeddem, and F. D'Auria, "Application of coupled code technique to a safety analysis of a standard MTR research reactor," Nuclear Engineering and Design, vol. 239, no. 10, pp. 2104-2118, 2009. 
[19] W. L. Woodruff, N. A. Hanan, R. S. Smith, and J. E. Matos, "A comparison of the PARET/ANL and RELAP5/MOD3. 3 codes for the analysis of IAEA benchmark transients," in Proceedings of the International Meeting on Reduced Enrichment for Research and Test Reactors, Seoul, Republic of Korea, October 1996.

[20] A. Hedayat, H. Davilu, and J. Jafari, "Loss of coolant accident analyses on Tehran research reactor by RELAP5/MOD3.2 code," Progress in Nuclear Energy, vol. 49, no. 7, pp. 511-528, 2007.

[21] C. Allison, J. K. Hohorst, A. Antariksawan et al., "Validation of RELAP/SCDAPSIM/MOD3. 4 for research reactor applications," Proceeding of the 13th International Conference on Nuclear Engineering (ICONE '05), Beijing, China, 2005.

[22] IAEA, Safety Analysis of Research Reactors, Safety Reports Series no. 55, IAEA, Vienna, Austria, 2008, STI/PUB/1321.

[23] ANSTO, "Preliminary Safety Analysis Report (PSAR). Replacement Research Reactor Facility," Australian Nuclear Science and Technology Organisation (ANSTO), 2001.

[24] IAEA, Safety Assessment of Research Reactors and Preparation of the Safety Analysis Report, IAEA Safety Series no. 35-G1, IAEA, Vienna, Austria, 1994.

[25] ANSTO, "Safety Analysis Report (SAR). Replacement Research Reactor Project," Prepared by INVAP for Australian Nuclear Science and Technology Organisation (ANSTO), 2004.

[26] ANSTO, "Probabilistic Safety Assessment (PSA) Summary for Public Release. Replacement Research Reactor Project," Prepared by Australian Nuclear Science and Technology Organisation (ANSTO), 2005.

[27] M. A. Navarro, F. L. A. Schweizer, and A. A. C. Santos, "Numerical investigation in the Brazilian multipurpose reactor pool," in Proceedings of the International Nuclear Atlantic Conference (INAC '11), Belo Horizonte, Brazil, October 2011.

[28] PLG, "Level 1+ Probabilistic Safety Assessment of the High Flux Australian Reactor (HIFAR)," 1998.

[29] IAEA, Component Reliability Data for Use in Probabilistic Safety Assessment, IAEA-TECDOC-478, IAEA, Vienna, Austria, 1988.

[30] IAEA, Generic Component Reliability Data for Research Reactor PSA, IAEA-TECDOC-930, IAEA, Vienna, Austria, 1997.

[31] CNEN, "Divisão de Fabricação e Projeto," Restrict Document, CNEN, 2012.

[32] CNEN, "Projeto preliminar do refletor do RMB," Restrict Document RMB-10100-RD-010, 2011. 


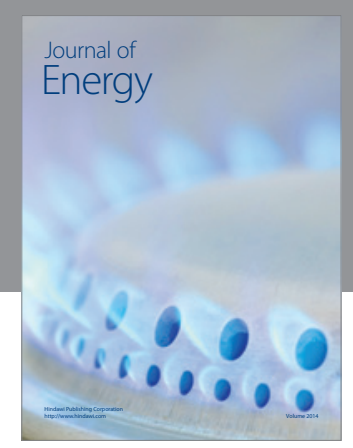

Journal of

Industrial Engineering
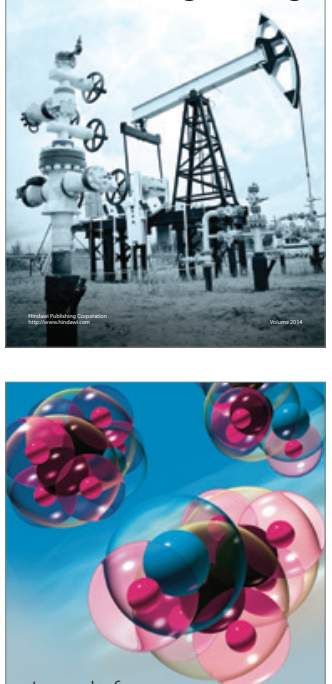

Fuels
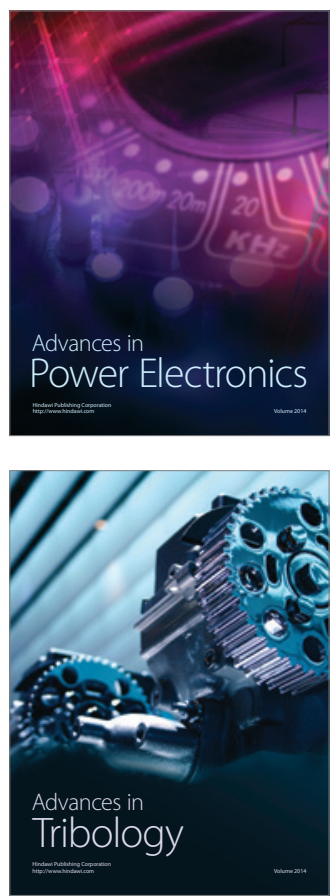

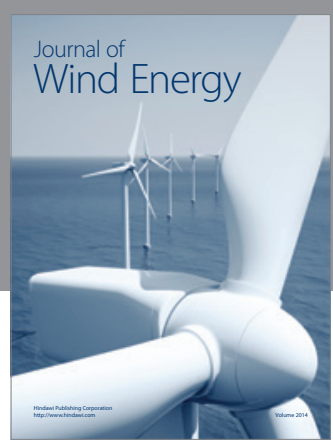

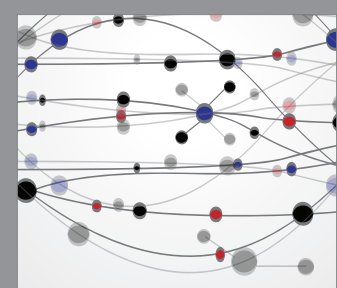

The Scientific World Journal

Submit your manuscripts at http://www.hindawi.com

Journal of

Structures
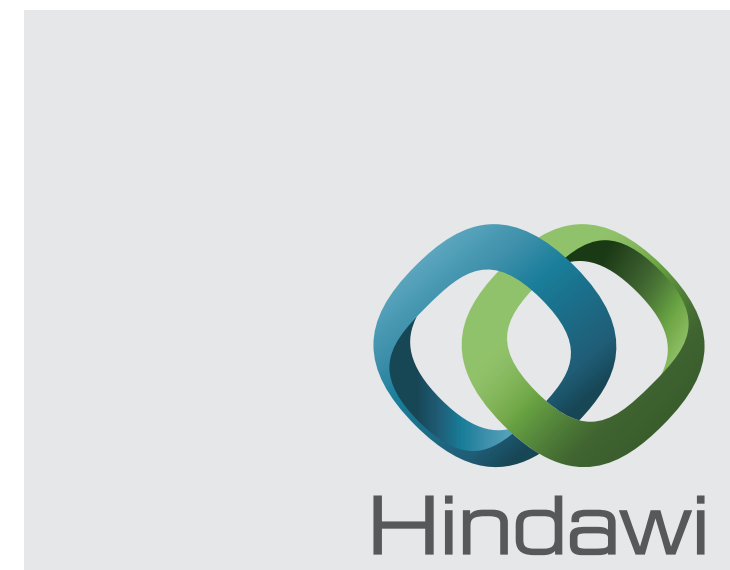

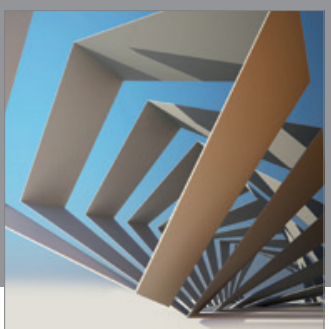

Rotating

Machinery
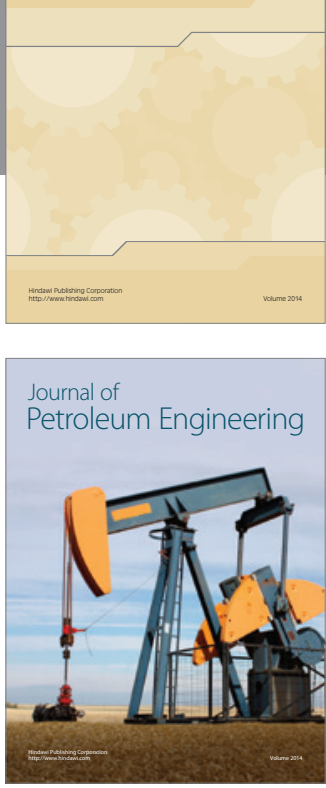

Journal of

Solar Energy
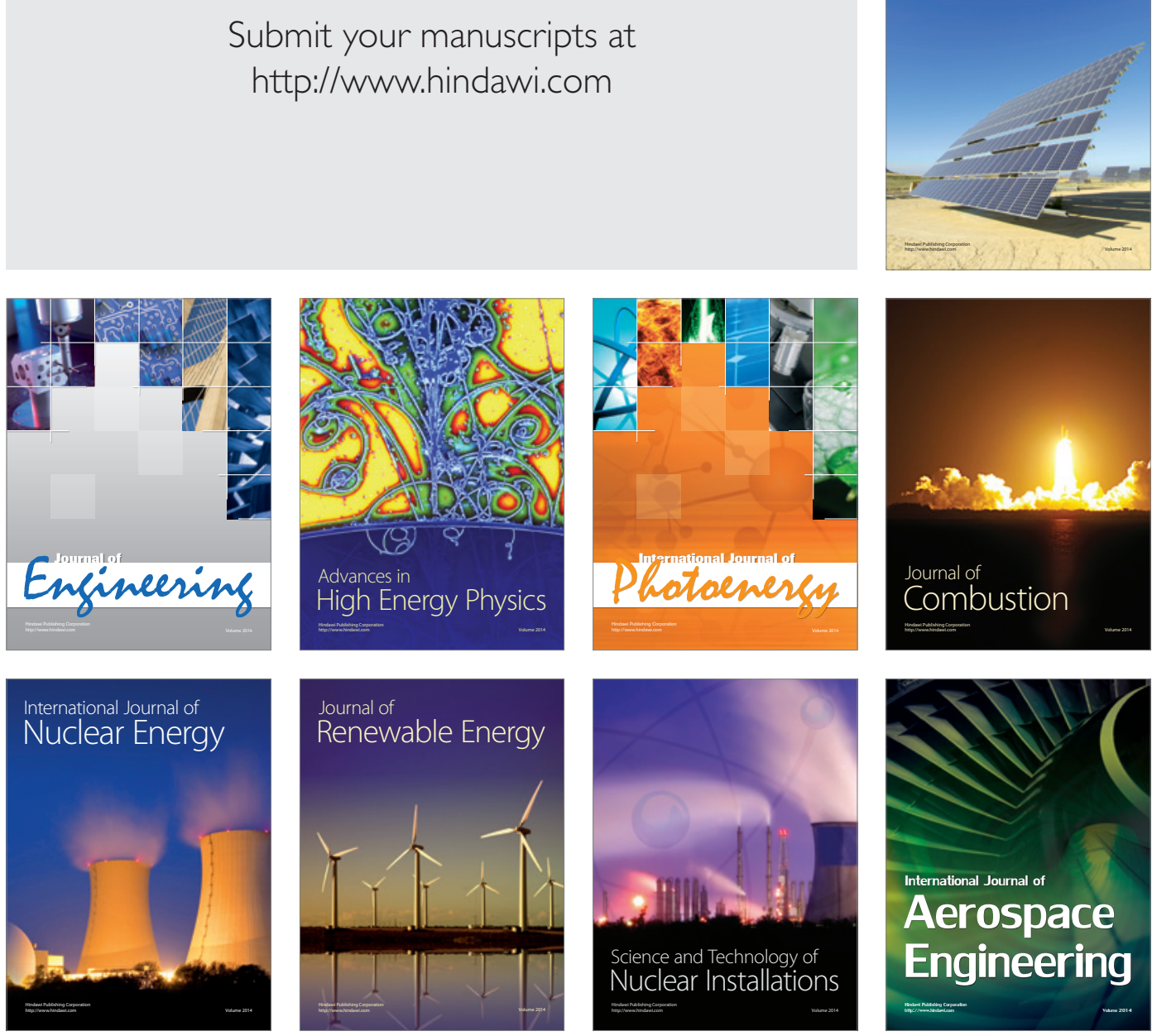